\title{
High-resolution autoradiographic studies of comparative nucleologenesis and genome reactivation during early embryogenesis in pig, man and cattle
}

\author{
V. Kopečný \\ Animal Production Research Institute, CS-104 00 Prague 10, Uhrínĕves, Czechoslovakia
}

(3rd Franco-Czechoslovak Meeting, INRA, Jouy-en-Josas, 13-14 December 1988)

\begin{abstract}
Summary - Using high-resolution autoradiography, simultaneous studies of ultrastructure and nucleic acid dynamics were performed during nucleologenesis in early porcine, human and bovine embryos. In contrast to the early genome activation known to occur during the second cell cycle in the mouse, the onset of rRNA synthesis detected by $(5-3 \mathrm{H})$ uridine incorporation in the nucleolar compartment is delayed by cleavage of one cell cycle (to the third cell cycle) in the early pig embryo and by two cell cycles (to the fourth cell cycle) in human and cattle embryos. Extranucleolar RNA synthesis, as detected by nucleoplasm labelling, generally started shortly before rRNA synthesis. The timing of nucleolar labelling was well correlated with the penetration of embryonic DNA into the nucleolus precursor body and with nucleolus structure differentiation. Ultrastructural and/or autoradiographic techniques are suggested for the study of the onset of embryonic transcription, e.g. in embryos "reconstructed" by micromanipulation.
\end{abstract}

Early embryo - transcription — pig - man - cattle

Résumé - Etude comparative par autoradiographie ultrastructurale de la nucléologénèse et de la réactivation du génome au début du développement embryonnaire porcin, humain et bovin. Cet article présente la synthèse des résultats obtenus par l'autoradiographie ultrastructurale sur la formation du nucléole et le début de l'expression du génome dans les embryons bovins, humains et porcins. Par rapport à l'embryon de souris, l'incorporation d'uridine $\left({ }^{3} \mathrm{H}\right)$ dans le compartiment nucléolaire est retardée d'un cycle cellulaire dans l'embryon porcin, et de deux cycles cellulaires dans les embryons humain et bovin. Comme lincorporation nucléolaire est concomitante de la pénétration d'ADN périnucléolaire dans le nucléole et de l'apparition du composant fibrillaire dense, l'ensemble de ces phénomènes correspond bien au début de la synthèse de l'ARNr. Le marquage du compartiment extranucléolaire précède de peu celui du nucléole. Comme cela commence à être confirmé par d'autres types d'expériences, l'activation du génome embryonnaire se produit à des stades différents dans les quelques espèces de mammifères étudiées.

L'emploi simultané de la microscopie électronique et de l'autoradiographie est proposé comme une technique de choix pour l'analyse de l'activité nucléaire, notamment dans des embryons "reconstruits" par micromanipulation.

Embryon précoce - transcription - porc - homme - bovin 
“... peut-on envisager une définition plus restrictive qui ne reconnaîtrait l'existence d'un nouvel être qu'après l'expression chimique du message génétique composite..."

Jacques Testart, I'CEuf Transparent.

\section{REACTIVATION OF EMBRYONIC GE- NOME AFTER FERTILIZATION}

Early embryonic animal development is characterized by an initial period during which the embryonic genome, composed of paternal and maternal contributions, remains inactive. Early development is directed by maternal RNAs of all classes already synthesized during oocyte growth and maturation and stored in the cytoplasm. The transitional period to the developmental control by the embryonic genome itself varies among species; rather than a sharp shift from maternal gene products to that of the embryo, there is a co-existence of gene products from these two genomic sources - maternal vs embryonic - for a certain period of time (Davidson, 1986).

In mammals, most of the published data concern mouse embryos (Johnson, 1981; Geuskens \& Alexandre, 1984). Studies on embryos from other mammalian species are scarce (see King et al., 1989; and Kopecny' et al., 1989a). For this reason we decided to study the process of the transition from the maternal to embryonic control in embryos of farm animals, as embryo transfer and genetic manipulation techniques are used at such early embryonic stages; and also in the human species in which in vitro fertilization and embryo transfer are primary concerns. In addition, all the species are phylogenetically distant from Rodentia.
The availability of early human and cattle embryos is evidently limited, so we concluded that the method of choice would be high-resolution autoradiography, a technique already used for the study of early embryonic development in mouse (see, Geuskens \& Alexandre, 1984). In fact, the application of this methodology has allowed us to investigate simultaneously in early pig, human and cattle embryos : (i) the ultrastructural morphology of nucleologenesis; (ii) the localization of embryonicDNA containing sites, especially in the differentiating nucleolus; and finally (iii) the onset of extranucleolar and nucleolar transcription. Based on the 3 parameters studied, these complex studies confirmed a different localization for transcription in early preimplantation embryos of pig, man and cattle, as far as the cleavage stage was concerned. Our findings suggest that the idea should be abandoned of equivalence in differentiation degree at a given division stage among different mammalian species, which leads to a somewhat mechanistic stage-to-stage comparison, and to unjustified extrapolations to other mammalian species of data pertinent to the mouse, e.g. the utilization of the number of cleavage divisions "in vitro" as a criterion of the normality of development. In addition, our findings outline the need to study the consequences of such diversity in onset of gene expression for the biology of the earliest phases of mammalian embryogenesis; especially in timing of relevant developmental changes at molecular and cellular levels which may be reflected, e.g. in the outcome of nuclear transplantation in the early embryo (Prather et al., 1987).

Our autoradiographic observations were confirmed by other methods of investigation of genome activation in early embryos of some of the same species (see below). 


\section{ULTRASTRUCTURAL MORPHOLOGY}

The main target of morphological observations was the nucleolus since marked changes in the formation of this organelle coincide closely with the period of transition from the maternal to the embryonic control in all 3 mammalian species investigated.

Soon after fertilization, a nucleolus precursor body (NPB) appears (for review and terminology used, see Tesariik et al., 1987b; Kopečný et al., 1989a). Although of different sizes, NPBs showed a high degree of similarity in all embryos from the 3 species investigated. The NPB is a spherical intranuclear body of uniform structure consisting of a dense network of filaments; in human NPB these filaments are about 3 $\mathrm{nm}$ thick and probably of proteinaceous composition only (Tesarik et al., 1987b). The NBP is most prominent in one- and two-cell pig embryos where it takes up to one-third of the nucleus diameter and is sharply delineated from the nucleoplasm (Tománek et al. 1989). NPB's are quite inconspicuous, however in cattle embryos until the early 8-cell stage (Kopečný et al., 1989a).

The morphology of the NPB transformation into a functional nucleolus differs unexpectedly in the 3 species investigated. In comparison to the morphology of embryonic nucleologenesis in mouse (Geuskens \& Alexandre, 1984) the smallest difference is seen in the pig. At the beginning of the four-cell stage, the first association of fibrillar centres with the periphery of NPB is seen (Tománek et al., 1989). Later, a rim of a typical nucleolonemal structure is gradually formed at the periphery of the NPB, showing a prominent dense fibrillar component and granular component as well (Tománek et al., 1989). In man, the ultrastructure of NPB is constant until the 8cell stage (Tesarik et al., 1986a). In con- trast to pig embryos, condensed chromatin usually forms, during this period, a continuous rim around the NPB. During the fourth cell cycle, NPB sharp boundary with the nucleoplasm is lost and the perinucleolar chromatin seems to be internalized within the NPB (Tesařík et al., 1986a). In contrast to mouse and pig embryos, the differentiation of the NPB into a functional nucleolus formed by intermingled typical nucleolar components and the disappearance/ obscuration of the primitive fibrillar component is a relatively rapid process in human embryos (Tesarík et al., 1986a, 1987b). A further difference to the pig embryo consists of the synchrony of nucleolar differentiation within a given nucleus (Tesarík et al., 1986a). In pig embryos, until the morula stage, all developmental steps of nucleologenesis may be seen within the same nucleus (Tománek et al., 1989) (Fig. 1). On the other hand, there is no synchrony between blastomeres constituting an early human embryo (Tesař́k et al., 1986a, b, 1988).

In the human embryo during the fifth cycle of cleavage, the nucleolus enlarges twice to the diameter of the NPB and the most of its volume is occupied by granular and fibrillar components and several interstices are observed (Tesarík et al., 1986a).

The greatest differences in the morphological events of nucleologenesis in comparison to the mouse are encountered in the early cow embryo. In the course of the 8-cell stage, probably during the second half of the 4th cell cycle, a large central lucid area develops in the NPB. According to the recent nucleolar terminology we named this entity "NPB-vacuole" (Kopečný et al., 1989a). At the beginning of the vacuole development, the appearance of its contents is similar to that of the nucleoplasm. A contemporary feature is the association of the NPB with prominent patches of condensed chromatin, attached to the NPB in relatively few and limited areas of 
contact. During further differentiation towards the typical nucleolar structure, secondary vacuoles appear (Fig. 2a; short transparent arrows), the primary vacuole loses its sharply delineated boundary and a clump of chromatin appears within it (Fig. 2a). Internalization of perinucleolar chromatin is seen (Fig. 2b; long arrows) and the first granules of the granular nucleolar component appear (Fig. 2a; centre of the white circle). In a very rapid subsequent development within the eight-cell stage, fibrillogranular nucleoli appear with fibrillar centres showing a typical nucleolonemal structure. Shortly after, the nucleoli lose their rounded shape by rapid accumulation of granular nucleolar component and occupy a considerable proportion of the nucleus (Kopečný et al., 1989a). This process takes place at least in some blastomeres of the 8-cell cattle embryo. During the final stages of nucleologenesis it is not possible to discern the primary embryonic component in NPB (Kopečný et al., 1989a).

Taken as a whole, the development of nucleoli in early mammalian embryo, notwithstanding the identical biological significance of their differentiation, shows considerable differences among species, in the cleavage stage at which nucleologenesis begins, in the number of cell cycles between the beginning and the completion of this process, and in the remarkable diversity of the morphology of the intermediate stages.

\section{FINE-STRUCTURE LOCALIZATION OF DNA-CONTAINING SITES}

Nucleolus precursor bodies do not contain embryonic DNA and the penetration of DNA into these entities from perinucleolar chromatin is an early step in the nucleologenetic process in man (Tesarík et al., 1986a, 1987b) as well as in cattle (Kopečný et al., 1989a, b). These conclusions were based on DNA labelling of cleaving embryos in vitro, for a time period which was more protracted than the expected length of the cell cycle by (methyl-3H) thymidine so that a general pattern of all replicated DNA distribution was obtained by autoradiographic analysis. In both species a close correlation was observed between the DNA-penetration process into NPB and morphological features of nucleologenesis and the onset of transcription (Table I). In early human embryos, Tesarík et al. (1987b) suggested that the penetration of DNA into NPB, i.e. the gradual association of rDNA with the proteinaceous component

Fig. 1. Extranucleolar and nucleolar transcription in an 8-16-cell pig embryo. Fine-structure autoradiograms show labelling after a 20 -minutes pulse with $(5-3 \mathrm{H})$ uridine. a. The differentiation of the nucleolus from the nucleolus-precursor body is extended over several divisions in early pig embryos and is asynchronous for the nuclei within one blastomere nucleus. It is thus possible to observe the array of differentiation events from the nucleolus-precursor body (1) to a functional nucleolus (III) in two nuclei of two neighbouring blastomeres. The onset of nucleolar transcription, an "early nucleolar transcriptional pattern" is also seen (II), with only a few autoradiographic grains at the periphery. Note also the extranucleolar labelling in the nucleoplasm and lack of labelling in the cytoplasm of all blastomeres, since after a short pulse with $(5-3 \mathrm{H})$ uridine only the localization of newly sythesized RNAs is seen $(x 2600)$. b. A higher magnification of the functional nucleolus (III) shown in Figure 1a. This nucleolus is still composed of a prominent remnant of the primitive fibrillar material, probably only proteinaceous material (PF) not involved in transcription. On its periphery, however, a typical nucleolonemal structure composed of the dense fibrillar component is covered almost completely by heavy labelling and surrounded by the granular nucleolar component (G), not yet labelled after the short-duration pulse. (x 26000 ). 
of the nucleolar "anlage" is a key event of nucleologenesis, triggering an array of processes leading to activation of rDNA transcriptional capacity followed by pre-rRNA processing later on. In cattle embryos, the local penetration of labelled DNA into the NPB was found to coincide with the appearance of the large central vacuole (Fig. $2 b)$. No labelling was observed in the vacuole. The inside of the differentiating nucleolus, however, was penetrated by embryonic DNA only in the next step of nucleolus development when secondary vacuoles were formed. Thereafter all vacuoles were a frequent site of labelling, in addition to other areas of the nucleolus (Kopečný et al., 1989a, b).

Another interesting feature connected with the onset of transcription is the intranuclear distribution of DNA in cattle embryos. Before transcription started, the labelled DNA was seen only at the periphery of nuclei. As soon as transcription started, DNA distribution became homogeneous throughout the nucleus (Kopečny et al., $1989 b)$. This phenomenon might be the result of a change in the compactness of the DNA molecule, organized in a loop anchored to the nuclear periphery which may be differently extended in relation to different functional states of the DNA, e.g. in relation to transcription.
Table 1. Localization of fibrillar centres appearance, of DNA penetration into NPB, and of extranucleolar and nucleolar transcription during the first cleavage divisions of embryos of mouse, pig, man and cow as detected by fine-structure autoradiography.

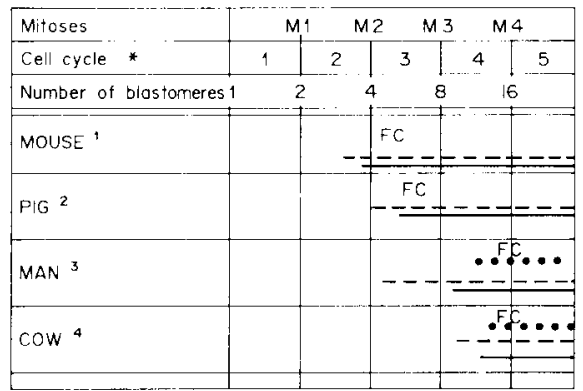

1 Geuskens \& Alexandre, 1984. ${ }^{2}$ Kopečný et al., 1985 Tomanek et al., 1986, 1989. 3 Tesařík et al., 1986a, 1987b. ${ }^{4}$ Kopečný et al., 1985; Camous et al., 1986; Kopecný et al., 1989a.

FC - first appearance of fibrillar centres; $\cdots$... detection of DNA penetration into NPB; - . . . - detection of extranucleolar transcription; - detection of nucleolar transcription.

\footnotetext{
* In many cases the observations were made on asynchronously dividing embryos. For this reason the description and localization of particular events necessitates reference to the cell cycle and not to the number of blastomeres.
}

Fig. 2. Nucleolus of a late 8-cell cow embryo. Fine-structure autoradiographic demonstration of a) transcription sites; b) DNA-containing sites. a. Late 8-cell cow embryos were pulse-labelled with $\left(5-{ }^{3} \mathrm{H}\right)$ uridine so that the sites of newly synthesized RNA were visualized. The nucleolus at this stage was formed of intermingled nucleolar components. The autoradiographic grains indicate the localization of the appearing dense fibrillar component inside the otherwise less dense fibrillar structure, probably corresponding to the proteinaceous nucleolar "anlage" of the nucleolus-precursor body. In addition, first granules of the granular nucleolar component are already formed (centre of the white circle). In the big primary vacuole a clump of dense chromatin is seen. Secondary vacuoles (short transparent arrows) appear. Other dense-fibrillar nucleolar compartment (long arrows) not showing labelling may represent the penetrating nucleolus-associated chromatin $(x 60000)$. b. Four-cell cow embryos were cultured in the presence of $\left(\right.$ methyl- ${ }^{3} \mathrm{H}$ ) thymidine so that after division to 8-cell stage all replicated embryonic DNA was labelled. In addition to an intensive extranucleolar labelling of all condensed chromatin, labelled DNA was detected inside the nucleolus. The intra-nucleolar labelling is interpreted as (perinucleolar) chromatin internalization leading to nucleolus differentiation from the NPB ( $x 38000$; ne : nuclear envelope). 
$6+3 \times a$

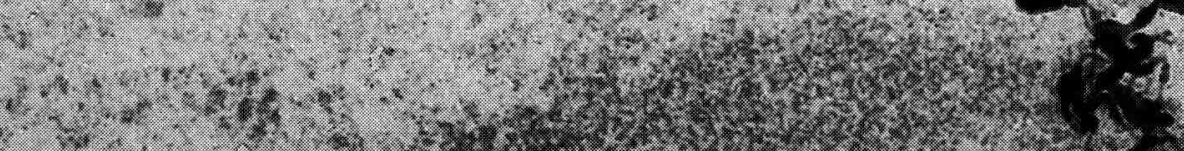

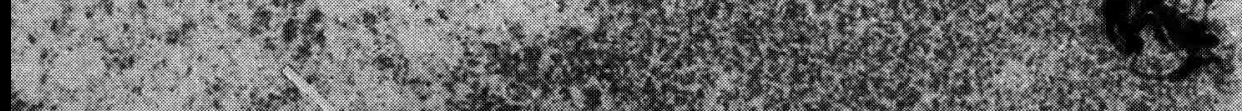

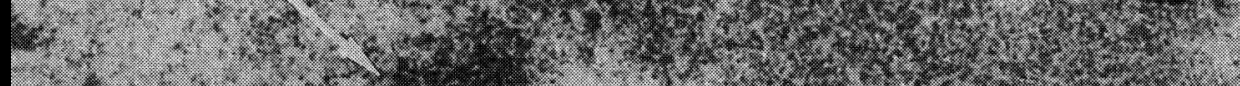

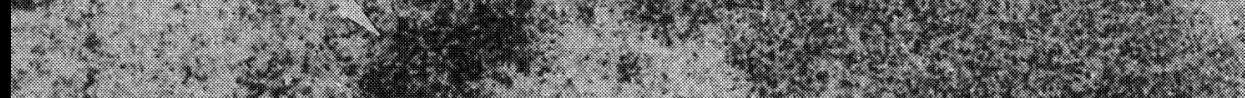

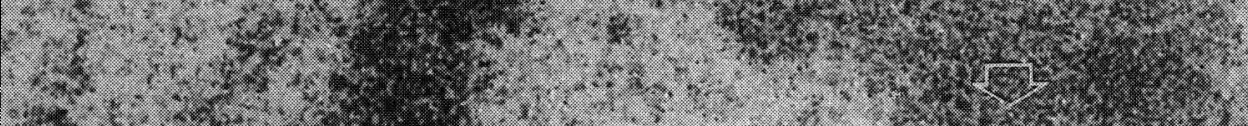

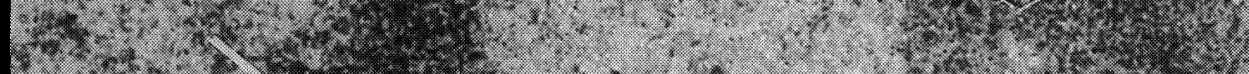





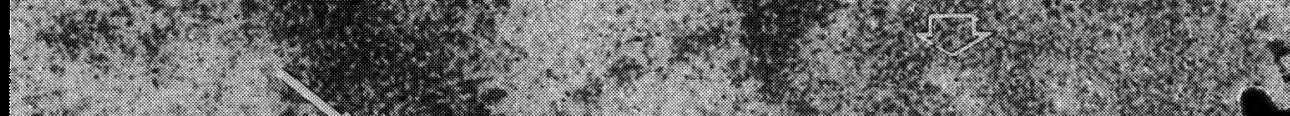

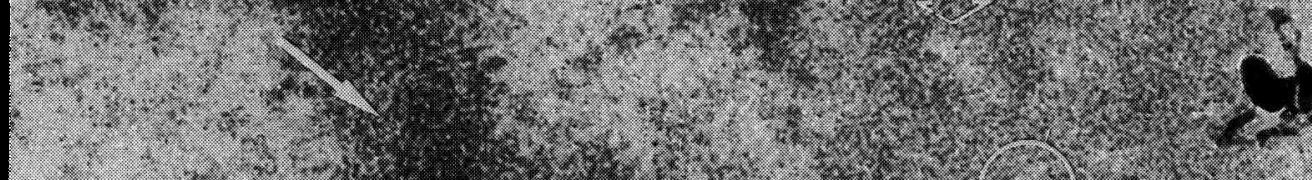

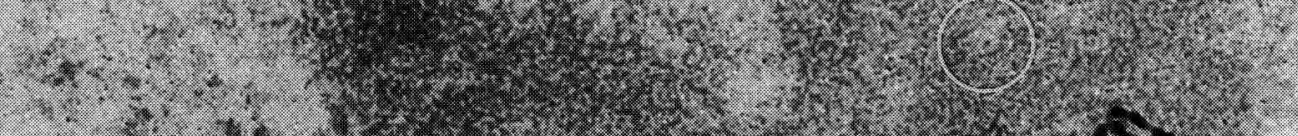

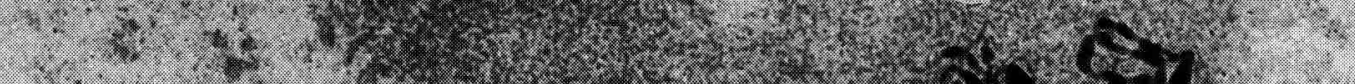

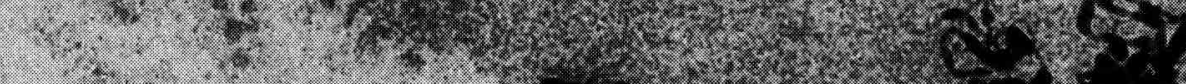

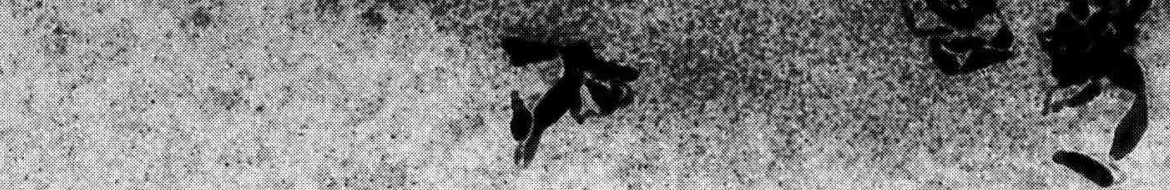

$4 \ddot{R}=$
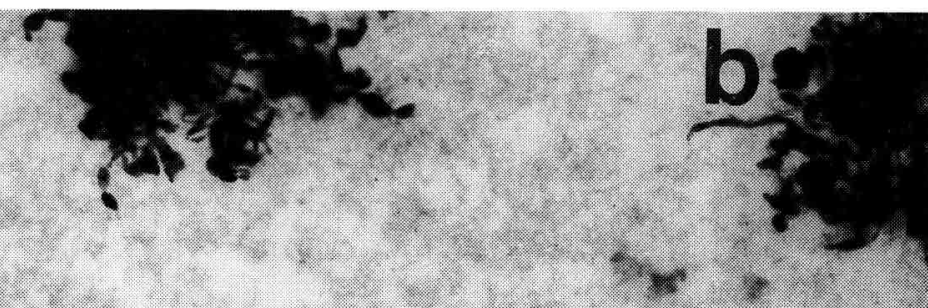

(2)

$\rightarrow i^{2}+x^{2}+2 k$

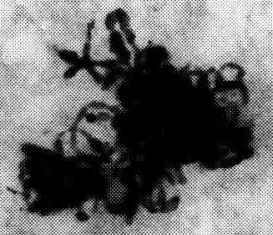

s.5

ㄴ. 슨.

(2)

.

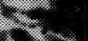

,

a

ad 4



a 


\section{NUCLEOLAR AND EXTRANUCLEOLAR TRANSCRIPTION}

The main aim of our ultrastructural autoradiographic studies was to detect the onset of transcription in early mammalian embryos by the allocation of labelling after a short $(20 \mathrm{~min})$ pulse of $(5-3 \mathrm{H})$ uridine in vitro to that stage of cleavage division at which the reactivation of embryonic genome occurs (Figs. 1, 2a). The validity of the results on the timing of the transition to the embryonic control of development in pig, man and cattle (see Table I) was confirmed by the simultaneous morphological changes already described and by observations of DNA interaction with the NPB. The extranucleolar labelling generally precedes nucleolar labelling in all investigated species (Table I). In human 8-cell embryos, a marked enhancement of both extranucleolar as well as nucleolar transcriptional activity was noted, but only in those embryos which continue their development (Tesařík et al., 1988; review Tesaŕík, 1988). This increase in labelling intensity has been named "progressed-cleavage" transcriptional pattern in contrast to a preceding phase with low or absent labelling in the "nucleolus which is named "early cleavage" transcriptional pattern. The proportion of blastomeres showing the progressed-cleavage transcriptional pattern was only about three-quarters at both 8cell and morula stages (Tesarík et al., 1986b). Production of ribosomes was detected only in blastomeres possessing the progressed-cleavage pattern of transcription (Tesarík et al., 1986b). Application of that observation to different developmental situations in early human embryos allowed us to detect failures in differentiation of some blastomeres (Tesařík et al., 1986b); it was indicative of a transcriptional defect in multinucleated blastomeres (Tesařík et al., 1987a) and finally led to the detection of the effect or early embryogenic genome activity on phenotypic changes at the subcelluiar level (Tesarík et al., 1988). However, whether a similar approach could be used in other mammalian species remains in question. In pig, in contrast to the human embryo, an asynchrony in nucleolar development within one nucleus is reflected in the simultaneous presence of "early" and "late" transcriptional patterns (Tománek et al., 1989) (Fig. 1a, II and III). In reconstructed bovine embryos the arrest of nucleolus structure differentiation has been observed for three consecutive cell cycles after blastomere fusion with an enucleated oocyte. An "early" transcriptional pattern emerged only in the fourth cell cycle (Kaňka et al., 1989), probably mimicking the usual situation in cattle embryos (Table I).

\section{DISCUSSION AND CONCLUSIONS}

The main advantage of the autoradiographic technique in the study of the onset of transcription during early mammalian embryonic nucleologenesis is the possibility of showing the structure function relationship even at the level of particular nucleolar components in a single blastomere nucleus. This is a unique approach to the heterogeneous early mammalian embryo. Furthermore, it was possible to reveal two different types of transcriptional pattern in an apparently uniform population of blastomeres forming either 8-cell or morula stage human embryos. Autoradiography thus offered a tool for many new insights into the biology of early preimplantation human embryo, particularly into the impact of the activity of the embryonic genome on developmental events (Tesarík, 1988), which would hardly be detectable by other experimental approaches. 
Correlation of structure and function, i.e. the coincidence of autoradiographic detection of the beginning embryonic of RNA synthesis or of the penetration of replicated embryonic DNA into the nucleolusprecursor body with the morphological features of nucleolus differentiation (Table I) was also a major criterion of our comparative analysis in different species.

Based on the present knowledge of the morphological support of nucleolar transcription in a variety of cells (Goessens, 1984) there was full agreement in the early embryos of all three investigated species between the first appearance of nucleolar labelling by $\left({ }^{3} \mathrm{H}\right)$ uridine and the formation of the dense fibrillar component of nucleoli (the first morphological sign of nucleolar transcription). On the other hand, in human and bovine embryos, the appearance of $\mathrm{fi}$ brillar centres was delayed in regard to the onset of nucleolar transcription (Table I).

Our studies on penetration of replicated embryonic DNA, labelled by $\left({ }^{3} \mathrm{H}\right)$ thymidine into the NBP (Tesařík et al., 1987b; Kopečny et al., 1989b) allowed us to identify clearly as DNA-containing structures the fibril originating in the perinucleolar chromatin and entering the NPB, a suggestion previously based on morphological analysis (Tesařík et al., 1986a). Extranucleolar transcription generally appeared to start in the embryos of all investigated species a little earlier that nucleolar transcription, and its localization was found on the borderline of the condensed chromatin as in other cell nuclei. A new interesting feature emerged from our studies of labelled DNA distribution at the onset of transcription in nuclei of 8-cell cattle embryos (Kopečný et al., 1989b), in that embryonic (labelled) DNA resettled stepwise to the central part of the blastomere nucleus after being localized, before nuclear transcription started, on the nuclear periphery.
The ontogenic localization of extranucleolar transcription in pig, human and cattle embryos (Table I) has also been tested in all experiments by light-microscope autoradiography whose sensitivity is known to be at least equal if not superior to the sensitivity of radiobiochemical measurements (Rodgers, 1987). The reliability of our autoradiographic data has been confirmed by various means of detection of the first embryonic genomic read-out. In human, sheep and cattle embryos using RNA-synthesis inhibitors, the sensitive period when embryonic RNA is essential for further development was localized to the 2cell stage in mice (Bolton et al., 1984; Kidder and McLachlin, 1985), but at the 4-cell stage in cattle embryo (Barnes, unpublished observation; cited by King et al., 1988), in between the 4-and 8-cell stage in human embryo (Braude et al., 1988) and at the 8-cell stage in sheep embryo (Crosby et al., 1988). The first transcription of embryonic genes revealed by the electrophoretic profiles of newly synthesized proteins has again been detected at the 2-cell stage of the mouse embryonic development (Flach et al., 1982) but only at the transition from the 4-cell to the 8-cell stage in the human embryo (Braude et al., 1988), or even at the progressed 8-cell stage in cattle (Barnes et al., 1987) and sheep embryos (Crosby et al., 1988). A sharp increased in heat shock protein 705 synthesis was observed at the 8-cell stage in cow embryo (Renard et al., 1988) and mRNA coding for hCG was first detected in 8-cell human embryo (Bonduelle et al., 1987). Last but not least, a specific localization, during ontogenesis, of a vulnerable "block stage", representing a difficult period for culture in vitro interestingly corresponds with the expected shift from maternal to embryonic control of development (see Camous et al., 1986; Tománek et al. 1989). 
Based on these different lines of evidence, it can be concluded, that the activation of the embryonic genome really occurs in the studied mammalian species at that cell cycle when the incorporation of $\left({ }^{3} \mathrm{H}\right)$ uridine was detected in nucleus and that the culmination of this process is the reactivation of nucleolar (= ribosomal RNA) genes, detectable both by morphological evidence of the nucleologenesis and by nucleolar $\left({ }^{3} \mathrm{H}\right)$ uridine incorporation. The possibility of a minute RNA synthesis below the sensitivity threshold of $\left({ }^{3} \mathrm{H}\right)$ uridine autoradiography cannot be excluded (Clegg \& Pikó, 1982), but it is suggested that such possible gene action in human zygote or 2-cell embryo shoud not be responsible for the control of major cellular events (Tesařik, 1988). The maternal control in early human and cattle embryos is probably prolonged and at the same time more complex, as suggested in the case of early human embryos (Tesarík, 1988).

It is expected that the biochemical evidence for genome reactivation in different mammalian species will accumulate to an extent similar to that in the mouse, when sufficient experimental material is provided by e.g. in vitro fertilization of ovarian oocytes (Barnes et al., 1987). On the contrary, the morphological and autoradiographic analyses remain the methods of choice in those experimental situations where single embryos or isolated blastomeres should be analyzed. This is the situation encountered at present in efforts of reconstructing cattle embryos by nuclear transplantation of single blastomere nuclei into enucleated oocytes. Since upto now the degree of success has differed considerably, an objective method for the assessment of the outcome of a micromanipulative procedure is necessary. In this situation the cytologic analysis based on fine-structure nucleolar morphology and autoradiography proved to be extremely helpful (Kañka et al., 1989). Briefly, these authors showed that the reconstructed cattle embryo was not able, in some cases, to establish its own synthesis of ribosomal RNA since the process of nucleolus differentiation was arrested for several divisions of the reconstructed embryo at the vacuolated NPB (Stage II; Kopečný et al., 1989a). Extranucleolar RNA synthesis and nucleoli with secondary vacuoles appeared in the fourth cell cycle in some embryos (Kaňka et al., 1989). Therefore the nucleolar morphology of the cattle embryo might inform researcher immediately of the result of the experimental procedure.

In conclusion, in mammalian embryos, as well as in more thoroughly studied somatic cells, the nuclear and nucleolar morphology and chromatin topochemistry reflect the state of their differentiation and function (King et al., 1989). The minute differences observed and discussed in this review may have been considered as of as purely academic interest just a short time ago. At present, they are, in the context of the efforts to understand the mechanisms of micromanipulative reconstruction of early mammalian embryos, among the information needed for further investigation in this promising field (Prather et al., 1987; Betteridge and Fléchon, 1988).

\section{ACKNOWLEDGMENTS}

We would like to express our thanks to Dr. Jacques Edmond Fléchon whose constant interest and support has been the basis of the Franco-Czechoslovak scientific collaboration amply reflected in this review. Critical reading of this paper by Dr. Jiri Kan̆ka is highly appreciated, as well as the editing by A. Bouvet. 


\section{REFERENCES}

Barnes F.L., Parrish J.J., Susko-Parrish J.L. \& First N.L. (1987) Morphological and molecular aspects of early development in the bovine. Theriogenology 27, 210 (abstr.)

Betteridge K.J. \& Fléchon J.E. (1988) The anatomy and physiology of pre-attachement bovine embryos. Theriogenology 29, 155-187

Bolton V.N., Oades P.J. \& Johnson M.H. (1984) The relationship between cleavage, DNA replication and gene expression in the mouse 2-cell embryo. J. Embryol. Exp. Morphol. 36, 609-622

Bonduelle M.L., Smets G., Liebaers I., Van Steirteghem A.C., Todd R., Worden J., Williamson R. \& Akhurst R. (1987) Gene activity in preimplantation human embryos. Hum. Reprod. 1 (suppl. 2), 83 (abstr.)

Braude P., Bolton V. \& Moore S. (1988) Human gene expression first occurs between the fourand eight-cell stages of pre-implantation development. Nature 332, 459-461

Camous S., Kopečný V., Fléchon J.E. (1986) Autoradiographic detection of the earliest stage of $\mathrm{H}^{3}$-uridine incorporation into the cow embryo. Biol. Cell 58, 195-200

Clegg K.B. \& Pikó L. (1982) RNA synthesis and cytoplasmic polyadenylation in the one-cell mouse embryo. Nature 295, 342-345

Crosby I.M., Gandolfi F. \& Moore R.M. (1988) Control of protein synthesis during early cleavage of sheep embryos. J. Reprod. Fertil. 82, 769-775

Davidson E.H. (1986) Gene Activity in Early Development. Academic Press, New York, 3rd edn.

Flach G., Johnson M.H., Braude P.R., Taylor R.A.S. \& Bolton V.N. (1982) The transition from maternal to embryonic control in the 2-cell mouse embryo. EMBO J. 1, 681-686

Geuskens M. \& Alexandre H. (1984) Uitrastructural and autoradiographic studies of nucleolar development and rRNA transcription in preimplantation mouse embryos. Cell Differ. 14, 125134

Goessens G. (1984) Nucleolar structure. Int. Rev. Cytol. 87, 107-158

Johnson M.H. (1981) The molecular and cellular basis of preimplantation mouse development. Biol. Rev. 56, 463-498
Kaňka J., Fulka J. Jr. \& Fulka J. (1989) Nuclear reprogramming after nuclear transplantation in bovine embryos (submitted)

Kidder G.M. \& McLachlin J.R. (1985) Timing of transcription and protein synthesis underlying morphogenesis in pre-implantation mouse embryos. Dev. Biol. 112, 265-275

King W.A., Chartrain I., Kopečný V., Betteridge K.J. \& Bergeron H. (1989) Nucleolus organizer regions and nucleoli in mammalian embryos. $J$. Reprod. Fertil. (in press)

Kopecný V., Fléchon J.E., Tománek M., Camous S. \& Kanka J. (1985) Ultrastructural analysis of $3 \mathrm{H}$-uridine incorporation in early embryos of pig and cow. ECBO 9th Nucleolar Workshop, Cracow, p. 31 (abstr.)

Kopečný V., Fléchon J.E., Camous S. \& Fulka J. Jr. (1989a) Nucleologenesis and the onset of transcription in the 8-cell bovine embryo : finestructural autoradiographic study. Mol. Reprod. Develop. 1, 79-90

Kopečný V., Fulka J. Jr., Pivko J. \& Petr J. (1989b) Localization of replicated-DNA containing sites in preimplantation bovine embryo in relation to the onset of RNA synthesis. Biol. Cell. 65 (in press)

Frather R.S., Barnes F.L., Sims M.M., Robl J.M., Eystone W.H. \& First N.L. (1987) Nuclear transplantation in the bovine embryo : assessment of donor nuclei and recipient oocyte. Biol. Reprod. 37, 859-866

Renard J.P., Barra J., Heyman Y., Babinet C. \& Bensaude O. (1988) Expression of heat shock proteins in early mouse and cow embryos. 3rd Franco-Czechoslovak Meeting, Jouy-en-Josas, Dec. 13-14, 1988

Rodgers A.W. (1967) Techniques of Autoradiography. Elsevier

Tesarik J. (1988) Developmental control of human preimplantation embryos : a comparative approach. J. In vitro Fertil. Embryo Transfer 5, 347-362

Tesařík J., Kopečný V., Plachot M., Mandelbaum J., Dalage C. \& Fléchon J.E. (1986a) Nucleologenesis in the human embryo developing in vitro: Ultrastructural and autoradiographic analysis. Develop. Biol. 115, 193-203

Tesařik J., Kopečný V., Plachot M. \& Mandelbaum J. (1986b) Activation of nucleolar and extranucleolar RNA synthesis and changes in the 
ribosomal content of human embryos developing in vitro. J. Reprod. Fertil. 78, 463-470

Tesařik J., Kopečný V., Plachot M. \& Mandelbaum J. (1987a) Ultrastructural and autoradiographic observations on multinucleated blastomeres of human cleaving embryos obtained by in vitro fertilization. Hum. Reprod. 2, 127-135

Tesarík J., Kopečny V., Plachot M. \& Mandelbaum J. (1987b) High-resolution autoradiographic localization of DNA containing sites and RNA synthesis in developing nucleoli of human preimplantation embryos : a new concept of embryonic nucleologenesis. Development 101, $777-791$
Tesarik J., Kopečný V., Plachot V., Mandelbaum J. (1988) Early morphological signs of embryonic genome expression in human preimplantation development as revealed by quantitative electron microscopy. Develop. Biol. 128, 15-20

Tománek M., Kopečný V. \& Kaňka J. (1986) Studies on RNA synthesis in early pig embryos. Histochem. J. 18, 138 (abstr.)

Tománek M., Kopečný V. \& Kaňka J. (1989) Genome reactivation in developing early pig embryos : an ultrastructural and autoradiographic analysis. Anat. Embryol. 180, 309-316 